\title{
STATE ANTI-DRUG HEALTH POLICY IN RUSSIA (ON THE EXAMPLE OF THE KHANTY-MANSIYSK AUTONOMOUS DISTRICT OF THE RUSSIAN FEDERATION)
}

\author{
Natalia Chevtaeva ${ }^{1}$, Elena Kachanova ${ }^{2}$, Natalia Makhova ${ }^{3}$
}

\begin{abstract}
In recent decades, the illicit drug problem within Russia's population has become more severe. The threat of drug addiction is not only socially unacceptable but, in general, is fast becoming a major public health problem in Russia. The study objective is to identify factors that determine the availability of support from the state anti-drug policy of Russia, as exemplified by the Khanty-Mansiysk Autonomous District, Yugra. Monitoring of the drug situation, carried out in KhantyMansiysk, Yugra in 2014 - 2016, provides the background data along with results of a sociological survey of 2000 residents, and input from an expert panel. Indicators of drug-related morbidity in Khanty-Mansiysk, Yugra, are compared with those for the Russian Federation as a whole. Parameters and criteria for providing access to health care for the population are established along with recommendations for the authorities on how to optimize drug treatment for the population. The monitoring not only provides data to identify the vulnerabilities but, with the accumulated positive experience from Russia, also assists those providing drug treatment to the population to focus efforts in alleviating this major social problem.
\end{abstract}

UDC Classification: 364; DOI: http://dx.doi.org/10.12955/cbup.v6.1210

Keywords: health policy, treatment, drugs, addiction

\section{Introduction}

The spread of drug addiction in the last century has become one of the most concerning social problems of modern society. According to the World Health Organization, the world has witnessed a continuous increasing trend in the number of people taking drugs, especially increased drug use by the youth (Berry \& Accelus, 2015). The use of non-conventional drugs has risen, synthetic drugs have become more widespread, and drug use is now represented in all socio-economic groups of society (Berry \& Accelus, 2015).

In Russia, a state policy for anti-drug use, The State Anti-Drug Policy of the Russian Federation 20102020, has been adopted. The Russian Federation Federal Law 'On Narcotic Drugs and Psychotropic Substances' defined the main tasks of providing anti-drug assistance to the population as improving public knowledge of the dangers associated with drug use; and develop and implement preventive measures to assist minors and youth to reject drugs (Chung \& Shek, 2008).

As Gossop (2013) writes, in developing and implementing the state anti-drug policy strategy, an analysis of the status and availability of drug treatment in Russia is required. Considering this, the present study aims to evaluate health policies and identify the factors that determine the availability of State Anti-Drug Policy in Russia (exemplified by Khanty-Mansiysk Autonomous District-Yugra).

Khanty-Mansiysk Autonomous Okrug, Yugra as one of the main oil-producing districts of Russia, ensures sustainable income for the population living on its territory. In nominal terms, the living standards in the Okrug-Yugra are the highest in the Russian Federation. Per capita, monetary incomes of the population of Yugra in 2016 amounted to 45.7 thousand rubles, while the average for Russia is 30.775 thousand rubles. The region remains highly attractive for labor migration, including potential drug users, from countries such as Tajikistan, Kazakhstan, and Kyrgyzstan.

Social policy is a priority in the budget policy of the Khanty-Mansiysk District. From the total volume of the consolidated budget for the autonomous region, over $60 \%$ is aimed at health, education, social policy, culture, physical culture, and sports.

\section{Data and Methodology}

Data from the state monitoring of the illicit drug situation in the Russian Federation during 2014-2016 were analyzed. The study also included a sociological survey and input from an expert panel. The

\footnotetext{
${ }^{1}$ Russian Presidential Academy of National Economy and Public Administration, Yekaterinburg, 620144, Russia, natalia.chevtaeva@ui.ranepa.ru

${ }^{2}$ Russian Presidential Academy of National Economy and Public Administration, Yekaterinburg, 620144, Russia, elena.kachanova@ui.ranepa.ru

${ }^{3}$ Russian Presidential Academy of National Economy and Public Administration, Yekaterinburg, 620144, Russia, natalya.makhova @ui.ranepa.ru
} 
results of the survey and expert advice provided the data for analyzing the degree of illicit drug availability, the motives for using narcotic substances, and the measures for counteracting the development of drug use.

The survey was conducted in 2014, 2015, and 2016 and involved 2000 residents representing all municipal and urban districts and cities of the Khanty-Mansiysk Autonomous District, Yugra. The information was collected through a formal interview at the place of residence of each respondent, aged 14 years or older. The research was conducted using a selective method of stratified random sampling, proportionally distributed by gender, age, and type of settlement. The proportion of males was $49.8 \%$ and females $50.2 \%$. The proportion of respondents from 14 to 25 years was $20.5 \%$, from 26 to 35 years $20.1 \%$, from 36 to 45 years $20.2 \%$, from 46 to 55 years $19.4 \%$, and over 56 years $19.4 \%$. The respondents were $81 \%$ urban residents and $19 \%$ rural.

The respondents represented different social and professional backgrounds. They included students of higher educational institutions (19.6\%), students of secondary professional educational institutions $(13.9 \%)$, school children (6.6\%), laborers (16.6\%), public servants (32\%), top-level managers (3.6\%), department heads $(7 \%)$, and unemployed or retired persons $(0.7 \%)$.

An expert panel comprised 50 experts of Khanty-Mansiysk Autonomous District-Yugra. These were from three categories: members of the anti-drug committees, representatives of the Federal Service for Drug Control, and representatives of the medical community. The expert panel was formed to identify the motives that deter the population from drug use.

Descriptive analyses (percentages, mean, and standard deviation) were performed using software SPSS (Statistical Product and Social Sciences) version 11.5.

\section{Results and Discussion}

The expert panel gave several factors as motives that deter people from using illicit drugs. These motives are a conscious negative attitude towards drug use, of particular, the popular synthetic drugs with their severe complications; the risk of early death; the risk of acquiring human immunodeficiency virus (HIV) and viral hepatitis; loss of respect from the family; and fear of losing family ties. At present, more and more young people acquire the relevant positive social values of education and highly skilled profession.

The comparative analysis of 2014, 2015, and 2016 years shows that obtaining illegal drugs is 'very easy' or 'relatively easy' for respondents. In summary, the positive responses as were defined in 2016 showed confidence in the availability of narcotic drugs had increased from 52.5\% in 2014 to $60.9 \%$ in 2016, after some downward fluctuation to $49.4 \%$ in 2015 (Figure 1).

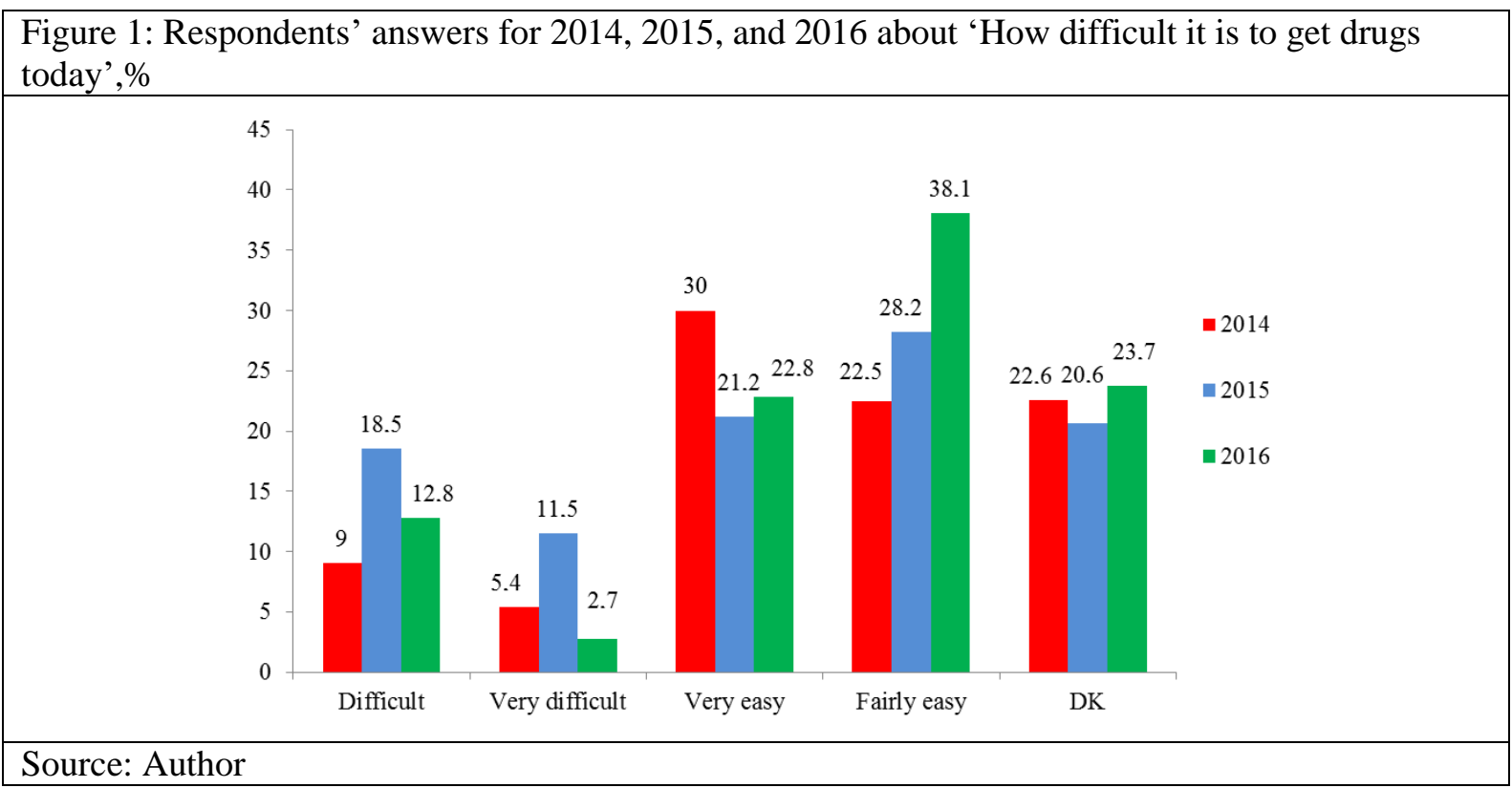

Respondents noted the places where illegal drugs were easiest to obtain in the previous years as being the Internet (23.5\%), nightclubs (14.8\%), apartments 12.6\%), and discotheques (8.7\%). It is positive 
that educational organizations had a low identification as a place to obtain drugs (4.7\%). As part of the sociological survey in 2016, the estimated prevalence of drug use was assessed. Almost a tenth of the respondents $(11.4 \%)$ admitted that they had tried narcotic substances, $88.6 \%$ answered a negative response to the question.

The main reasons for using illicit drugs, according to those who admitted trying them, were: interest and curiosity (34.2\%), consumption because of friends' asking (15.9\%), the desire to have fun $(12.2 \%)$, or idleness $(10.0 \%)$.

The age at which the respondents first tried narcotic substances varied. The highest proportion were those stating they had tried narcotics for the first time when aged between 16 and 18 years (46.0\%), followed by those stating they were aged between 19 and 25 years (27.6\%), then those answering they were aged between 12 and 15 years (14.6\%), and those aged between 26 and 34 years (5.9\%). Those trying narcotics for the first time at the age of 12 years represented $4.2 \%$ of respondents, while those trying for the first time between ages 35 to 49 years represented only $1.7 \%$ of respondents.

Youth companionships were the predominant place to first try the illegal drugs, according to the respondents' responses. They answered they first used these drugs when visiting friends and acquaintances for the first time (29.3\%), when on the street, in the yard, and at the entrance to the nightspot $(21.8 \%)$; and when in the clubs and at discotheques (13.8\%). Emphasizing the complex nature of the problem of drug addiction, experts identified social, organizational, and psychological reasons for the spread of illicit drug use in the Khanty-Mansiysk Autonomous District, Yugra.

The spread of drug addiction is facilitated by social processes such as the migration of young people from small settlements to large cities, the weakening of parental control, the lack of jobs for young professionals, and young people unable to 'find themselves' and their relevance in the social environment. Further, positive changes, such as free access to the Internet and the development of road infrastructure are also actively used by illegal drug distributors. Lack of proper control by society and not a stable value system and the worldview of the younger generation, lack of organized leisure can lead a person to the path of drug addiction.

Experts also identified that many intoxicating substances remain unrecognized as narcotic substances, and their trade is not prohibited in the territory of the Russian Federation (accordingly, the consumption of such substances is not illegal).

According to the experts, the socio-psychological reasons refer to "the desire of people to try something new and have fun; the desire to get social approval from friends, to stand out or get away from social problems". Experts focused on the lack of communication skills among young people, "young people can't communicate normally (communication is poorly developed) because everyone communicates through the Internet". They also noted the lack of full communication within the family, boredom, and idleness, and the lack of positive examples and sustainable worldview.

The results of the 2016 survey show that the leading motive in restraining from using illicit drugs (respondents who did not try and did not use narcotic substances) was the conscious choice of refusing the drugs $29.2 \%$ (compared to $30.9 \%$ in 2015 and $55.1 \%$ in 2014).

Concerns about the risk of contracting HIV and viral hepatitis B and C (15.5\%), an early death $(13.5 \%)$, and the threat of complete addiction $(11.8 \%)$ formed the next set of motives for restraining from using illicit drugs. This set was followed by the social aspects: fear of losing respect for loved ones and fear of excommunication from family (about 10\%).

In defining ways to solve the problem of drug addiction, $19 \%$ of respondents preferred a punitive method of toughening penalties for drug offenses. A similar mood within the population was observed in 2015 and 2014 with this measure regarded by $18 \%$ of respondents as a priority in the fight against drug addiction.

The next three priority measures, according to respondents, are as follows: compulsory treatment of drug addicts (about 16\%); social orientation, e.g., expansion of work with youth, assistance in socialization, increasing accessibility of psychologists, and psychotherapists (about 14\%); Hope for professional assistance from specialists in the field of preventing drug dependence (about 12\%).

Methods that are related to the material equipment of narcological assistance, such as building rehabilitation centers (10\%) and expanding the network of anonymous cabinets (9\%), were not among 
the priorities, according to the respondents. Most likely, such a response is explained by the image of a high level of equipment at medical organizations that provide assistance to drug addicts.

A set of measures to counter the development of drug addiction was proposed by the expert panel. These measures were that every citizen takes responsibility for the drug problem and that there is a need to reject a position of non-interference and to strengthen anti-drug propaganda. According to the expert panel: "Strengthen the struggle of law enforcement agencies against illicit drug trafficking by toughening penalties for the production and distribution of drugs; carry out activities aimed at improving the interaction of law enforcement agencies, local government, representatives of health and education".

It is necessary, according to experts, "to intensify and systematize work in educational institutions: to provide in each educational institution the position of a specialist responsible for the work on the prevention of drug abuse"; and "Involvement of volunteer movement and public organizations in the prevention work".

The study results showed that the drug problem in the Russian Federation regions was most acute in economically developed areas, which include the Khanty-Mansiysk Autonomous District, Yugra.

As a comparison, the rate of drug-related morbidity in the Russian Federation is 227.2 per 100 thousand, in the Ural Federal District to 263.1 per 100 thousand, whereas in Khanty-Mansiysk, Yugra, this figure reaches 302 per 100 thousand people (Figure 2). However, the planned operation of medical services in 2016 made it possible to reduce the prevalence of drug addiction in the district from 334.1 in 2014 and 302.7 in 2015 to 255.8 per 100 thousand of the population (4162) in 2016 (Figure 2).

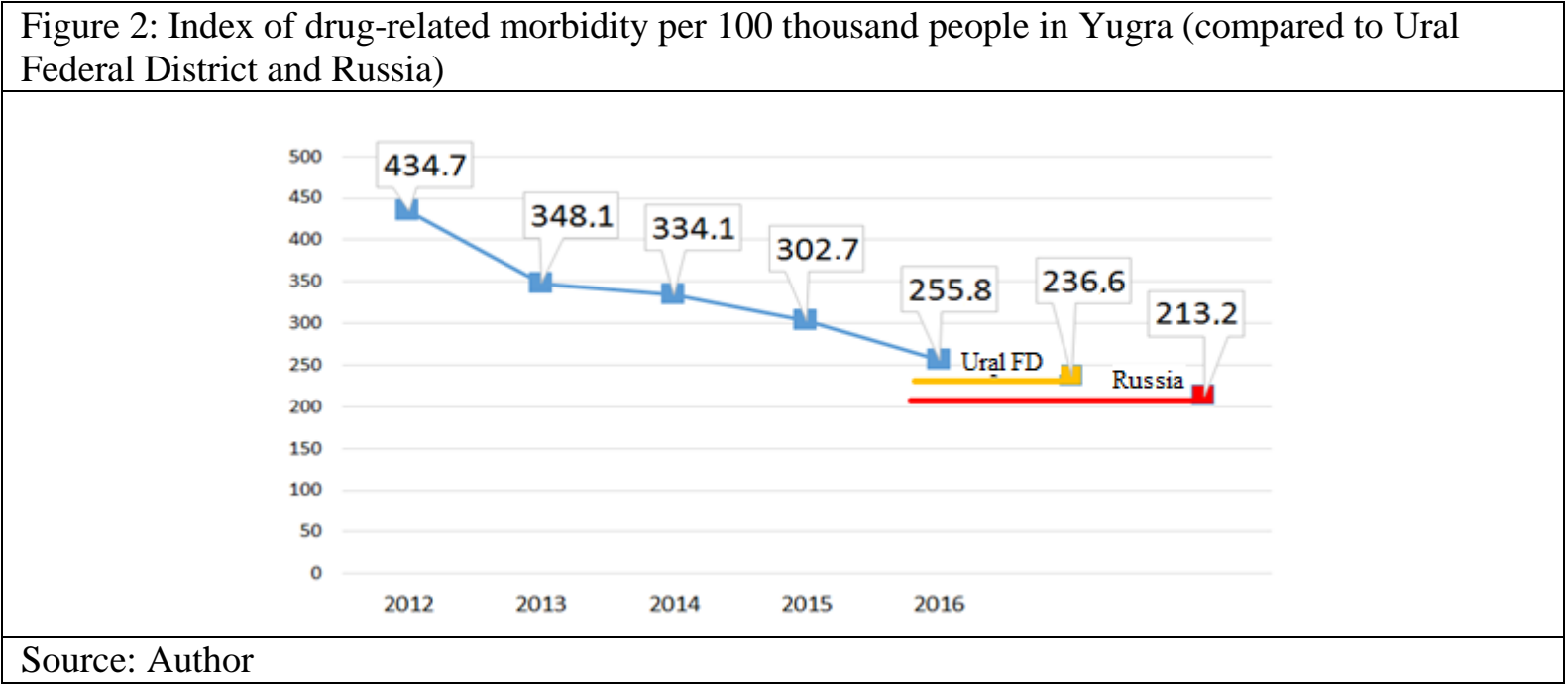

Figure 3 shows the primary incidence rate (i.e., the number of drug addicts who first applied for medical treatment in the current year) in the Khanty-Mansiysk Autonomous Okrug, Yugra, in 2016 was 15.3 per 100 thousand people ( 249 people), which is $27.0 \%$ lower than the level of 2015 , when the primary incidence rate was 21.0 per 100 thousand people (338 people).

In general, the level of primary morbidity in the Khanty-Mansiysk Autonomous Okrug, Yugra, is $36.3 \%$ lower than in the Urals Federal District (in 2015, 24.0 per 100 thousand population) and 8.5\% higher than the average for the Russian Federation (in 2015, 14.1 per 100 thousand of the population). The excess of the level of morbidity in drug addiction in the Khanty-Mansiysk Autonomous District, Ingra, in comparison with the average for the Russian Federation is due to the availability of state narcological assistance, the intensive detection of narcological disorders among the population, the availability of drug treatment services, and the large coverage of the able-bodied population by preliminary and periodic medical examinations.

The analysis revealed that the provision of narcological assistance to the population in the territory of Khanty-Mansiysk-Yugra Autonomous District is performed by medical institutions on three levels: the first level is the municipal (primary specialized health care); the second level is drug treatment (interdistrict-intermunicipal); the third level (regional). 


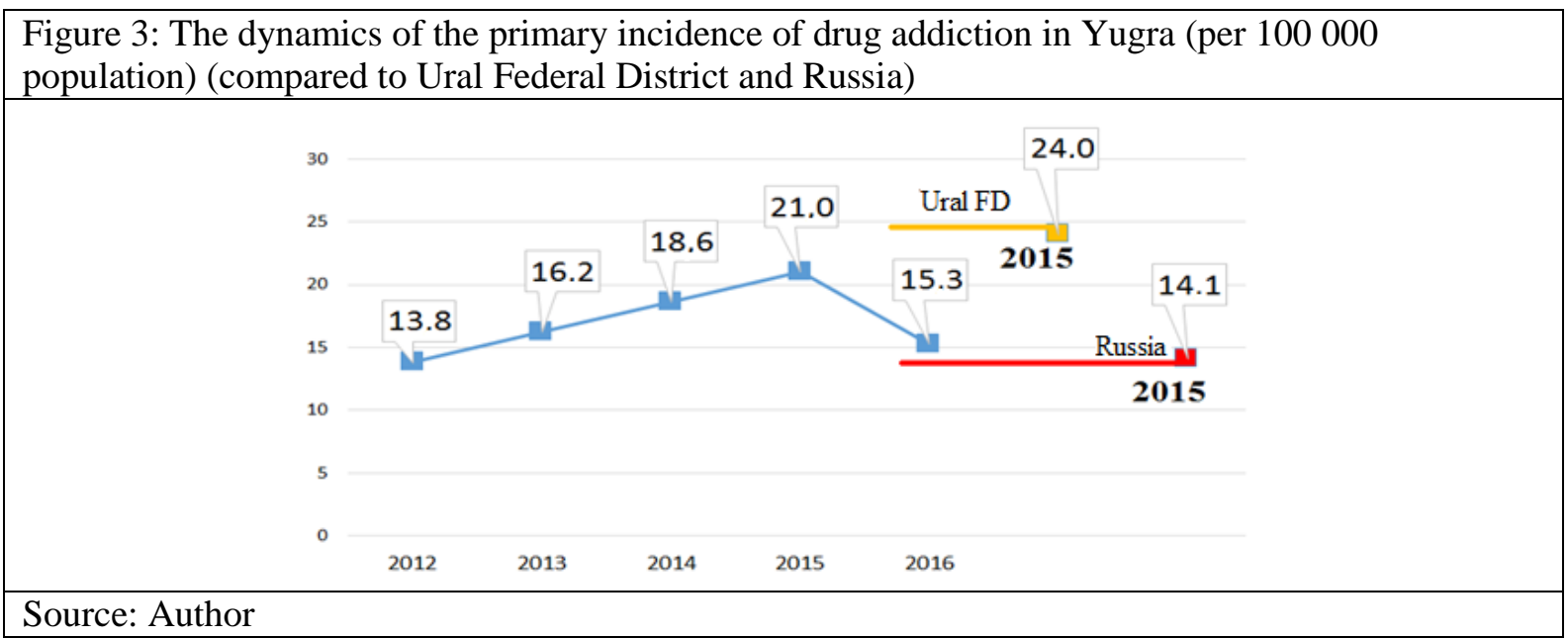

To improve the quality of social services provided by departments servicing drug addicts and their family members, a state standard of social services for Khanty-Mansiysk-Yugra was developed and approved in 2012. Gossop (2013, p.282) called it the "Social rehabilitation and re-socialization of people, allowing non-medical use of narcotic drugs and psychotropic substances". As a result of implementing the standard in the Khanty-Mansiysk, Yugra, a register of families in a socially dangerous situation was formed.

Among the dysfunctional families who gave their consent to be included in the registry, the leading cause of ill-being recorded was alcoholism (75\%), followed by families where the parents (legal representatives) failed to fulfill their responsibilities in raising and caring for children (18\%), and then substance abuse (3\%).

For all identified families, interagency plans of individual preventative and rehabilitation work were developed, including arrangements for rehabilitation work with parents.

To increase the availability of social services in the framework of the state program, Social Support for the Residents of Yugra for 2014-2020, certificates for payment of services for social rehabilitation and re-socialization of citizens suffering from drug-related diseases were provided. The certificate was provided by the Autonomous District budget. The total payments on the certificate were 35490 rubles (US\$522), which is the cost of rehabilitation. In 2015, all 40 certificates that were scheduled were implemented. By January 1, 2016, from 40 people who received a certificate, 33 undertook a course of rehabilitation, while 7 were in rehabilitation. Haerens and Zott (2013) found that this experience was unique to the Russian Federation and recommended it be extended to other territories of the Russian Federation.

To increase the motivation of illicit drug users to undergo social rehabilitation, the state informs its citizens about these services:

- Individual counseling on the official 'Phoenix' Center website (fenix-nv@bk.ru). This involved discussion of problems in the social networks in the area of social rehabilitation of drug addicts, as well as practical advice from professionals on rehabilitation and their social environment (codependent people);

- Placement of details about the list of organizations recommended for citizens suffering from drug use and addiction; and

- Telephone services, including social and psychological service 'Hotline' and service of emergency psychological aid to a single all-Russian number 'Child helpline'.

According to the results of the 2015 opinion poll of 2000 people, the availability of narcotic drugs had grown. Respondents were asked to rate how difficult it was to obtain drugs today. Half of the respondents noted the relative availability of drugs as 'very easy' $(21.2 \%)$ or 'relatively easy' $(28.2 \%)$. One-third of respondents said it was 'hard' to acquire drugs $(18.5 \%)$ or 'very difficult' $(11.5 \%)$. One in five found it difficult to estimate, selecting the answer 'do not know' (20.6\%).

Respondents noted the places that were easiest to buy drugs. The most popular distribution channels of drugs, according to respondents, were Internet networks (15.2\%), nightclubs (14.1\%), discos (11.1\%), 
and flats $(10.8 \%)$. Slightly rarer were the responses of 'the market' with $8.4 \%$, public places $6.9 \%$, a drugstore $6.5 \%$, educational institutions $6.9 \%$, and near home $2.4 \%$.

Mandatory or alternative drug treatment became available. Previously, many convicted people had no supervision of a psychiatrist. In 2015, 221 patients were appointed by a court for drug addiction treatment. This number is $39 \%$ more than in 2014 (159). In 2015, 139 people completed the full course of treatment. The number of those who discontinued treatment was $79.4 \%$ (175 people) and those who rejected the treatment $3.1 \%$ ( 23 people). In 2014, the share of those who finished the treatment amounted to $69.7 \%$ and those who discontinued the treatment $28.9 \%$.

Thus, the analysis of effectiveness and accessibility of specialized medical anti-drug assistance in the region led to the following conclusions:

1. Targets for the modernization of the Khanty-Yugra Drug Service for 2015, as part of the modernization of the Russian Federation drug service until 2016, were achieved as follows:

a. The number of drug addicts per 100 patients who were in remission from 1 year to 2 years in 2015 was 10.2, which is higher than the target for Russia by 1.2 times (8.8 per 100 drug addicts).

b. The number of drug addicts per 100 patients who were in remission for more than 2 years in 2015 was 18.9, which is higher than the target in Russia by 2 times ( 9.4 per 100 drug addicts).

c. The ratio of drug addicts who were re-hospitalized within one year is $22.6 \%$, which is below the target of $29.2 \%$ of the Russian Federation.

2. The prevalence of drug use in the Khanty-Yugra continues to decline. In 2015 the rate was 302.7 per 100 thousand people while in 2014 this was 334.1, a decline of $9.4 \%$. At the same time, an increase in primary addiction occurred in the region (Figure 3 ).

The availability of narcological assistance is achieved by the following organizational factors.

Exceeding levels of drug addiction in the Khanty-Yugra compared to the average for the Russian Federation is due not only to the economic welfare of the region but also to the availability of state drug treatment, intensive detectability of drug use among the population, equipped drug service, and a high coverage of health inspections for the working population.

In 2015, a moderate growth rate in illicit drug use and the number of registered drug users coincided with an increased number of examinees for the consumption of narcotic drugs. In particular, in line with modern drug services, specialized equipment was purchased that availed the opportunity to identify other chemical toxic substances, synthetic drugs, in biological fluids of the human body that previously were not detectable in practice.

The excessive level of morbidity in drug addiction in Khanty-Mansiysk Autonomous District-Yugra, in comparison with the average in the Russian Federation is explained not only by the economic wellbeing of the region but also by the availability of state narcological care, the intensive detection of drug addiction among the population, the availability of a narcological service, and the large coverage of able-bodied population by medical examinations.

The increase in the primary incidence of drug addiction is due to the widespread use of synthetic narcotic drugs through 'bookmarks' and the way they are acquired via the Internet. In addition, the spread of synthetic drugs is affected by the educational and labor migration of the population to populated areas during the holidays and rest.

Thus, the analysis of the drug situation in the Khanty-Mansiysk District led to the following general conclusions:

1. There is a wide coverage of the population through public services that identify people who use drugs;

2. Systematic work on the motivation of drug users to undergo treatment for drug addiction, medical, and social rehabilitation is carried out;

3. Access to drug treatment by the public through public health institutions is free of charge;

4. No system of private drug treatment services exists;

5. High provision rate of drug treatment, beds, and narcologists (figures exceed the average Russian figures). 
These indicators signify the availability of drug treatment in the Khanty-Mansiysk-Yugra is of a high level.

Anticipating a further development of the drug situation, experts have noted that there is a high probability of an increased number of multi-drug users. There is a high probability of the emergence of new drugs and drugs that have intoxicating effects on the human body, not included in the list of narcotic drugs, psychotropic substances, and their precursors. Such synthetic 'designer' drugs, 'designers', whose availability is currently at a high level, will be more widespread. The expert medical community of Khanty-Mansiysk, Yugra, has formulated a number of proposals on optimization of the anti-drug aid to the population.

According to experts, on a federal level, it is necessary to generate a list of organizations that are qualified to meet the requirements of inclusion into the national system of comprehensive rehabilitation and re-socialization of drug users.

At the interregional level, it is necessary to solve organizational interaction issues when drug addicts are directed to other regions of the Russian Federation, with the settlement of inter-budgetary relations of the Russian Federation.

The clinical diagnostic laboratories of medical institutions lack a library of mass spectra of the components of smoking mixtures (synthetic drugs). However, even with such libraries, it is not possible to perform research to identify the synthetic drugs in biological fluids. This is because the current legislation fails to regulate the methods of preliminary studies for synthetic drugs, the extraction of the narcotic drugs included in the synthetic drugs from biological fluids, and the information about the metabolism of the components of synthetic drugs in the human body.

It is necessary for the Khanty-Mansiysk District Health Department and the Department of Social Development of Yugra, to forward the necessary information onto the Department of Economic Development of Khanty-Mansiysk, Yugra for placement on notice boards. This action would inform citizens about the network of rehabilitation centers as the economic development premises is a multifunctional center of state and municipal services, located on the territory of the Autonomous District. The Khanty-Mansiysk District Health Department, Yugra, could also consider the expansion of the technical capabilities of health organizations to identify synthetic substances in human biological environments with the early stages of consumption, as well as the timely updating of the equipment and its modernization.

\section{Conclusion}

An evaluation of data from the ongoing monitoring of illicit drug use identified not only the vulnerabilities but also the positive experiences concerning illicit drug use in the Khanty-Mansiysk, Yugra, and other territories of the Russian Federation. The findings of this evaluation will help those entities involved in providing drug treatment to the population to concentrate their efforts on alleviating this major social problem.

\section{References}

Agarwal, R., Daher, AM., Mohd Ismail, N. (2013). Knowledge, practices and attitudes towards adverse drug reaction reporting by private practitioners from Klang Valley in Malaysia. Malays J Med Sci.20(2):52-61. PubMed PMID: 23983578; PubMed Central PMCID: PMCPMC3744000.

Barrientos-Gutierrez, T., Vidaña-Pérez, D., Zepeda-Tello, R., Hernández-Ávila, M. (2016). Regulating illegal drug markets: what legal markets can teach us. Lancet.;387(10037):2505. doi: 10.1016/S0140-6736(16)30796-6. PubMed PMID: 27353682.

Berry, MD., Accelus, TR. (2015). Business of Health: Business of Healthcare. Issue Brief Health Policy Track Serv.1-76. PubMed PMID: 27116766.

Chang, HY. Lyapustina T, Rutkow L, Daubresse M, Richey M, Faul M (2016). Impact of prescription drug monitoring programs and pill mill laws on high-risk opioid prescribers: A comparative interrupted time series analysis. Drug Alcohol Depend.165:1-8. doi: 10.1016/j.drugalcdep.2016.04.033. PubMed PMID: 27264166.

Chung, YY, Shek, DT. (2008). Reasons for seeking treatment among young abusers in Hong Kong. Int J Adolesc Med Health.;20(4):441-448.

European Monitoring Centre for Drugs and Drug Addiction (2013). European drug report: trends and developments. Luxembourg: Office for Official Publications of the European Communities.

Gossop, M. (2013). Living with drugs. 7th ed. Farnham, Surrey; Burlington, VT: Ashgate;. 282.

Haerens, M., Zott, LM. (2013). Prescription drug abuse. Detroit: Greenhaven Press. 255. 